\title{
Atlantis
}

Critical Studies in Gender, Culture \& Social Justice

Études critiques sur le genre, la culture, et la justice

\section{Intersectionality. 2nd Edition}

\section{Keisha Jefferies}

Volume 41, Number 2, 2020

Gender and the Canadian Armed Forces

URI: https://id.erudit.org/iderudit/1076204ar

DOI: https://doi.org/10.7202/1076204ar

See table of contents

Publisher(s)

Mount Saint Vincent University

ISSN

1715-0698 (digital)

Explore this journal

Cite this review

Jefferies, K. (2020). Review of [Intersectionality. 2nd Edition]. Atlantis, 41(2),

99-101. https://doi.org/10.7202/1076204ar

This document is protected by copyright law. Use of the services of Erudit (including reproduction) is subject to its terms and conditions, which can be viewed online.

https://apropos.erudit.org/en/users/policy-on-use/
This article is disseminated and preserved by Érudit.

Érudit is a non-profit inter-university consortium of the Université de Montréal, Université Laval, and the Université du Québec à Montréal. Its mission is to promote and disseminate research.

https://www.erudit.org/en/ 


\section{Book Review}

\section{Intersectionality. $2^{\text {nd }}$ Edition}

Keisha Jefferies is a Toronto-based African Nova Scotian woman, born and raised in New Glasgow, Nova Scotia. She is a registered nurse and $\mathrm{PhD}$ candidate in the School of Nursing at Dalhousie University. Her research examines the leadership experiences of African Nova Scotian nurses and the implications for nursing practice and education. Her scholarly and advocacy work focus on addressing anti-Black racism in nursing, equitable admissions in post-secondary institutions, and social justice at large. Keisha has clinical and policy experience in the areas of neonatal intensive care and breastfeeding. She is a Junior Fellow with the MacEachen Institute of Public Policy and Governance at Dalhousie. Her research is funded and supported by Vanier Canada Graduate Scholarships (Vanier-CGS), Killam Trust, Research Nova Scotia, Johnson Scholarship Foundation, BRIC NS, and the Faculty of Graduate Studies and School of Nursing at Dalhousie.

Book under review: Collins, Patricia Hill and Sirma Bilge, eds. 2020. Intersectionality. 2nd Edition. Medford: Polity.
7 he second edition of Intersectionality by Collins 1 and Bilge (2020) is a timely release and muchneeded follow-up to the first edition published in 2016. The authors tackle important questions and issues related to intersectionality and challenge both the current understanding and applications of the concept. Collins and Bilge effectively expand upon content from the first edition while also addressing the growth and expansion of intersectionality.

The text begins with a comprehensive definition of intersectionality: " $[\mathrm{H}]$ ow intersecting power relations influence social relations across diverse societies as well as individual experiences in everyday life" (2). The introduction is followed by case studies that examine three different contexts to demonstrate application of intersectionality: the FIFA World Cup, global economic inequality, and the Black women's movement in Brazil. "These cases both introduce important core ideas of intersectional frameworks and demonstrate different uses of intersectionality as an analytical tool" (5). This case-study approach facilitates understanding of the six core ideas or key concepts of intersectionality: social inequality, intersecting power relations, social context, relationality, social justice, and complexity. These six key concepts, according to Collins and Bilge, constitute the foundation of intersectionality and provide guidance for its use as an analytical tool. The remainder of the text is dedicated to exploring key criticisms and considerations of intersectionality in relevant areas such as neoliberalism, social media/digital activism, extremism, identity politics, reproductive justice, social protest, workers' rights, critical education, and academia.

By investigating three distinct cases, Collins and Bilge demonstrate how intersectionality is relevant in a multitude of contexts with varying degrees of complexity through the application of intersectionality as an analytical tool. These examples, paired with salient discussion about the mis/use of intersectionality in 
academia, displays the robust potential of this analytical approach across disciplines. For example, the authors describe how the interconnectedness of theory and praxis has caused confusion in academia, particularly as institutions scale up diversity, inclusion, and equity initiatives. In academic spaces, this confusion is dangerous as intersectionality may be wielded in ways that ultimately reinforce the very inequity and oppression that it is intended to eliminate. Collins and Bilge suggest that efforts to sustain critical praxis may place well-intended people and programs "on a slippery slope leading to watered-down understandings of diversity" (212). Further, "diversity initiatives have increasingly jettisoned structural analyses of social inequality in favor of individual and cultural interpretations of social problems" (211). Paradoxically, the mis/ use of intersectionality has led to more nuanced antiBlack racism, colonialism, heteronormativity, class oppression, and ableism. This confusion and misuse underscore the persistent struggle between academia, activism, and intersectionality.

Fittingly, the authors address pertinent questions regarding the use of intersectionality, such as: Does intersectionality always include an analysis of race or gender or sexuality? Without providing an explicit answer to such questions, the authors' emphasis on the six key concepts within intersectionality and the ways in which these concepts are interconnected and interdependent elucidate possible answers.

While this edition addresses new issues and questions, there are two additional and more immediate areas that are left under-examined. First, the authors employ intersectionality as an analytical tool to interrogate how systems of oppression influence individuals, groups, and societies through the use of six key concepts. Yet, beyond these well-articulated concepts, the authors offer no clear instruction for how to practically "apply" or do intersectional analysis. In other words, application of the six key concepts provides some guidance as to how one may approach this work yet a pragmatic, detailed explanation of doing intersectionality remains elusive. For some readers, this pliability is welcomed as it permits the often-desired flexibility needed to address social issues. Further, it is difficult and problematic to prescribe a set formula to highly contextual complex issues. However, for those unfamiliar with or new to critical social theory or for those who require a more pragmatic method of analysis, a "how to" may be appreciated.

The second drawback relates to how intersectionality is juxtaposed with Indigenous ways of knowing. Given the extensive colonial elements embedded within Western theory, a more extensive discussion of decolonization and Indigenous ways of knowing is vital. Toward the end of the text, the authors briefly discuss ways in which intersectionality and Indigenous ways of knowing are situated in academia. Collins and Bilge also repeat throughout the book that many pertinent conversations had to forgo richer discussion. Moreover, the authors acknowledge that many of the issues that were left unpacked would require in-depth exploration in a separate chapter or a text. However, a deeper discussion of how Indigenous ways of knowing have influenced the concept of intersectionality and, conversely, how intersectionality may compliment or hinder Indigenous knowledge systems is necessary. For example, how does intersectionality align, compliment, and/or inhibit the use of other approaches, specifically decolonial and anti-racist frameworks?

The above critiques notwithstanding, the second edition of Intersectionality aligns well with the field of critical theory and contains many notable strengths. The writing style is accessible to an audience beyond academia. The authors provide a clear and comprehensive definition of intersectionality to serve as an anchor for those interested or invested in intersectionality, particularly as an analytical tool. Yet the text is also in-depth enough to be intellectually rewarding for critical readers. An added strength of this text is the inclusion of an informative and fulsome discussion of the genealogy of intersectionality, which highlights the contribution of writers who preceded Crenshaw, including Toni Cade Bambara (1970), Frances Beal (1969), and the Combahee River Collective (1977). By introducing these early writers, Collins and Bilge provide vivid examples of how the fundamental ideas inherent to intersectionality were applied long before there was a mainstream term. This 
allows the authors to challenge misconceptions surrounding the evolution of intersectionality. Moreover, incorporating critical excerpts from these essential, formative works supports the argument for maintaining the connection between theory and praxis.

In summary, Collins and Bilge provide a useful guide to understanding and analyzing the complexities of the world through their interpretation of intersectionality and the six core ideas contained within. This text is a must-read for anyone looking to label their work as intersectional. The authors speak directly to readers open to receiving critical content that challenges traditional knowledge systems by using examples that resonate with a large, diverse audience. The text includes a solid genealogy of intersectionality and applies the theory to various complex and contemporary issues. It also strongly encourages readers to engage with many of the works that have informed intersectionality, primarily to avoid fragmentation, i.e. the separating of theory from praxis. Understanding the evolution of intersectionality not only strengthens the connection between theory and praxis, it also facilitates use of the concept in ways that align with the intended purpose of identifying and challenging oppression. As an essential text, this edition situates itself well within the larger critical social arena by aligning with the current pulse in academia, activism, and our dynamic social environment. 